\title{
Mixing and Dispersion of Pollutants Emitted from an Outboard Motor
}

\author{
Rong Situ ${ }^{1}$, Richard J. Brown ${ }^{2 *}$ \\ ${ }^{1}$ School of Engineering and Physical Science, James Cook University, Townsville, Queensland \\ 4814, Australia \\ *Tel: +61-747814172, Fax: +61-7-47816788, Email: rong.situ@jcu.edu.au \\ ${ }^{2}$ School of Chemistry, Physics, and Mechanical Engineering, Queensland University of \\ Technology, GPO Box 2434, Brisbane, Queensland 4001, Australia \\ *Corresponding author
}

\begin{abstract}
This paper quantifies the mixing and dispersion from an outboard motor by field experiments in a small subtropical waterway. Organic dye was used as a surrogate for exhaust emissions and was mixed with uncontaminated creek water before being dispersed into the creek. Dye concentrations were measured with an array of concentration probes stationed in the creek. The data were then processed and fitted with a power law function. The corresponding dispersion constants agreed well with the literature. However, the amplitude was lower than the IMO equation but higher than the correlation from laboratory tests. Results for dye concentration intermittency (presence of dye) are presented for the first time from such field measurements and show significant mixing in-homogeneity.
\end{abstract}

Keywords: Four-stroke outboard emissions, mixing, dispersion, emission modeling, outboard pollution, intermittency 


\section{Introduction}

Water pollution is any chemical, physical or biological change in the quality of water that has a harmful effect on any living organism. Pollution of rivers, lakes and oceans with contaminants has become one of the most crucial environmental problems of the twenty-first century. Worldwide, water and air quality problems are in urgent need of attention in terms of the pollutants themselves, and the problems are often seen to have international and global impacts (Masters, 1998). Despite recognizing this, human beings have indirectly learned to adapt to this problem and, thus, continue to cause further contamination of the world's precious resources.

Biological and industrial wastes have been frequently disposed of in estuaries for the sake of convenience. Each year, industries around the world produce millions of tonnes of chemical waste and may use no other way of disposing of it than discharging it into waterways. The chemical waste not only eradicates marine life, but also it stays in the water source for a very long time, causing the degradation of water quality. In 1998-1999, Eprapah Creek in Queensland, Australia, was heavily polluted by the illegal discharge of tributyltines (TBT) and other chemical residue. As a result, its water quality was measured by the Queensland Environmental Protection Agency (QEPA, 2004). The testing found that the water quality was low. The creek water lacked nitrogen and phosphorus which are essential for plant growth. In addition, poor dissolved oxygen levels indicated that the creek water had a very low oxygen supply for aquatic organisms. This creek was chosen as the field site for the test.

Recreational boating such as outboard and personal watercraft are important causes of water quality degradation (Kelly et al. 2005). Also, emissions from these engines are responsible for gaseous emissions into the world's atmosphere. Kimo International Sweden (2004) stated that, in the North Sea region, the number of pleasure boats operating on two-stroke engines was estimated to be about 1 million; also, these craft were contributing about 20,000 tonnes of hydrocarbons into waterways and the air every year. Concurrently, more than 10,000 tonnes of unburned engine oil was being emitted into the water with the exhaust gasses. By comparison, four-stroke engines do not mix oil with fuel as do two-stroke engines and are more 
fuel-efficient and cost competitive. However, they still contribute about 2.5 percent of their fuel to the water (Warrington 1999).

To study the mixing and dispersion of emissions in the wake of a vessel, laboratory experiments have been performed to measure the velocity and concentration field characteristics of a submerged swirling water jet discharged from a model boat propeller (Situ et al., 2010). The flume measurements were conducted in the zone of established flow up to 50 propeller diameters downstream of the propeller. The results showed self-similarity in the near field (up to 20 propeller diameters from the propeller). In another finding, the rapid mixing of contaminants from the release point gave a reduction in centreline concentration by a factor of $7 \times 10^{-5}$ after 50 propeller diameters. In contrast to such laboratory experimental studies, actual boats operating in waterways will be more complex as the results will be magnified greatly due to the higher velocities, higher turbulence, and the complexity of the natural environment.

In the literature, the well-known International Maritime Organization (IMO) formula (IMO, 1975) was developed based on field and laboratory tests. It suggested that the dilution ratio in the wake of a ship is proportional to $t^{0.4}$, where $t$ is time after discharge. The full-scale measurement of waste dilution has been tested with various types of ships: a moving barge (Ball and Reynolds, 1976), a US Navy frigate (Katz et al., 2003), and an aircraft carrier (Hyman et al., 1995). The results from these experiments showed that the dispersion constant, which is the exponent of time $t$, should be adjusted to fit with different datasets. For example, Ball and Reynolds found that the dispersion constant was in the range of 0.4 to 1.6 , which is in agreement with the value of 0.61 found by Katz et al., (2003).

Lewis (1985) proposed a theoretical model relating the dispersion of the effluent field to the turbulence intensity, and formulated two equations, for the intermediate stage and the long-term stage respectively. Chou (1996) divided the mixing process into three stages: near wake $(x / B<7$, where $x$ is downstream distance, $B$ is ship width); far wake $(7<x / B<100)$; and long-term diffusion $(x / B>100)$. He 
subsequently found theoretically that the dispersion constant should be 0.552 for the far-wake stage and 1.5 for the long-term stage.

In previous work, many researchers performed experiments in laboratories, where the working conditions were relatively stable. This enabled researchers to easily obtain satisfactory results without considering environmental effects such as weather, tide velocity, stratification and recirculation. Furthermore, the field experiments to measure the dilution ratio were mostly performed from an ocean-going ship at sea, which is a different condition from a small waterway. In this study, a field test was conducted in a small subtropical creek upstream of an estuary. The concentration of dye (surrogate pollutant) released from an outboard motor was measured in the wake of the propeller. The mixing and dispersion of pollutants was investigated and the statistical characteristics of the concentration fluctuations were studied.

\section{Experimental method}

As the experiment to measure the mixing and dispersion of emissions from an outboard motor in a waterway was the first study of its kind, the experimental method had to be chosen carefully. First, it was important to understand that the turbulent action created by the propeller would make it difficult to examine the mixing of pollutants in the water. Second, the pollutants emitted from the exhaust of any outboard engine are invisible to the human eye, and hard to measure in the field with existing instrumentation. Hence, highly concentrated organic tracer dye was introduced to visualize the mixing action. Finally, the dye had to be ejected into the mixing region at the back of the propeller, where the rapidly rotating propeller blades would draw the dye into the mixing region. This was necessary in order to simulate the location of exhaust release in an actual outboard motor. Subsequently, the mixture of the creek water and dye would be allowed to disperse slowly from the boat plume. Fast response concentration probes were used to detect the dispersed dye.

\subsection{Experimental site}

On-site field experiments were conducted in a small subtropical creek, Eprapah Creek, at Victoria Point, Queensland, Australia. Jones et al. (1999) reported that this small 
tidal creek which flows into Moreton Bay is approximately $15 \mathrm{~km}$ long, $2 \sim 5$ metres deep, and has a standing body of water at low tide. About $3.8 \mathrm{~km}$ of the total length is estuarine. The experiments were conducted about $2.1 \mathrm{~km}$ upstream from the opening of Eprapah Creek into Moreton Bay. It should be noted that the Victoria Point sewerage treatment plant is located $2.6 \mathrm{~km}$ from the mouth of the creek.

The previous investigation of water quality and turbulence characteristics close to this site have been described by Chanson et al. (2005) and Treventhan et al. (2008b). These can be used, where appropriate, to give a background description of the flow field in Eprapah Creek at the time of the propeller dispersion experiments. In these papers the site designated 2B was approximately $100 \mathrm{~m}$ upstream from the site of the current experiment. Treventhan et al (2008b) made a thorough study of this estuarine creek by deploying three acoustic Doppler velocimeters and two water quality probes at a variety of depths and transverse locations approximated $10 \mathrm{~m}$ from the left bank. They found that the top $1 \mathrm{~m}$ of water was relatively well mixed above the stratification boundary between more dense seawater below and well mixed water above in this region. The water depth at high tide was over $2 \mathrm{~m}$ at the location of the current outboard experiments making the region of mixing by the outboard motor clear of this variable density layer close to the bed stratification.

In this investigation it was important to avoid meandering sections because of secondary flow. The presence of such increased flow complexity might interfere with the experimental observations and subsequent interpretation. For instance, the dye might be interrupted by turbulent flow in the creek. Hence a relatively straight section, shown by a red oval in Figure 1, was chosen for the experiment.

\subsection{Field site equipment and instrument setup}

Figure 2 is a schematic diagram of the equipment setup. A generator was used as the main power source. To avoid any data loss in case of power failure, a UPS system was used as a backup power supply. A total of 5 concentration probes sent signals to a five-channel controller box (voltage supply unit manufactured by Masatoyo, P/L, Osaka, Japan) which displayed the analogue voltage from 0 to $1.2 \mathrm{~V}$ (Madhani and 
Brown, 2008). The gain and offset of the amplifier were adjusted so that a reading of 1 $\mathrm{V}$ on the gauge signified 8 parts per million ( $\mathrm{ppm}$ ) of concentration detected by the probe.

The concentration probe was custom-manufactured by Masatoyo P/L. A light beam in the red part of the spectrum is emitted from a light-emitting diode (LED) in the rear section and reflected at the probe tip. The probe tip also has a small opening where the solution passes through. Thus, attenuation of the light beam's intensity by blue dye is sensed and designated as a signal to the probe controller box which converts the signal to a voltage reading which, in turn, has a linear response to variations in the solution concentration. The voltage data are then sent to the analogueto-digital converter which has a sampling frequency of $1000 \mathrm{~Hz}$ and a computer for further processing. In the experiment, the capability of the concentration probe was limited to $12 \mathrm{ppm}$ due to the functionality of the probe controller box. The concentration probe was calibrated for $8 \mathrm{ppm}$ of Methylene Blue solution, with an accuracy of $\pm 5 \%$. The frequency response of the probes is approximately $100 \mathrm{~Hz}$ and is dependent on the velocity. A detailed description and characterization of the linearity and frequency response of the probes was presented by Madhani and Brown (2008).

Since five concentration probes were to be placed in the creek, it was necessary to design a holder to position them (Figure 3). The holder consisted of four main components: a footing, a 6.5-meter-long arm, a 3-metre-long aluminium beam, and several floats. The steel footing was constructed to be anchored in the soft, muddy riverbank. On one side of the arm, a hinge joint was used to allow a single degree movement according to the changing tidal height. The beam was designed to place the probes close to the centre of the creek. The five probes were attached to the beam, which was supported by plastic bottles as floats. The concentration probes were positioned vertically $150 \mathrm{~mm}$ below the water surface and $600 \mathrm{~mm}$ apart, with probe 1 positioned nearest from the riverbank. 
Figure 4 is a schematic diagram of the field deployment. The concentration probes were located away from the bend in the creek to avoid a secondary flow effect. In addition, a SonTek 3D acoustic Doppler velocimeter (ADV) (10MHz) was attached to a triangular pole array near the probes to determine the background velocity field of the main channel and any disturbance caused by the mixing action of the outboard motor (Chanson et al., 2005). The distance from the ADV measurement volume to the water surface was $500 \mathrm{~mm}$. A cross-sectional view of the creek at low tide is shown in Figure 5, which plots the depths of 29 positions in the creek measured using manual surveying equipment (Trevethan et al., 2008ab). The $0 \mathrm{~m}$ level presents mean sea level.

\subsection{Organic tracer dye solution setup}

As pointed out earlier, to study the mixing and dispersion of emissions from an outboard motor, a highly concentrated organic tracer dye was used to simulate the pollutant. Based on the requirements of the concentration probe, the dye had to be dark and intense enough to block the light beam at the tip of the probe. Several types of common dye were investigated, and it was concluded that Methylene Blue dye was the best. This dye has been used in similar laboratory experiments using the same concentration probe (Situ et al., 2010).

In the field test, 10 litres of Methylene Blue solution with a 25,000 ppm concentration was stored in two drums on a boat. A bilge pump delivered the dye solution at a constant flow rate of $0.7 \mathrm{l} / \mathrm{s}$ from the drums to an $18 \mathrm{~mm}$-ID dye injection pipe, which was mounted on the upstream of the $23.5-\mathrm{cm}$-diameter boat propeller, as shown in Figure 6. The experiments were conducted with a Honda 4-stroke single overhead cam (SOHC), 2-cylinder spark ignition internal combustion engine. The full throttle range is between 4950 and $5500 \mathrm{rpm}$, and the rated power is $8 \mathrm{HP}(5.9 \mathrm{~kW}) @$ $5000 \mathrm{rpm}$. The outboard engine was installed on the back of a recreational boat with a 3-metre draft (length) and a 1.5 metre beam (width).

\subsection{Experimental procedure}

On $29^{\text {th }}$ September 2006, the instruments and equipment were first installed in the creek. The concentration probes and the dye pumps were then calibrated. The boat 
initially idled perpendicular to the probe beam and facing upstream with distance of $1.0 \sim 1.5$ metres, as shown in Figure 4. Just before the boat moved, organic tracer dye was injected into the creek at a flow rate of $0.71 / \mathrm{s}$. The engine throttle was set at half to three quarters when the boat started to move upstream. After the boat had travelled 10 metres from the probes, the dye injection was stopped. The concentration probes and the ADV recorded the data and sent it to the computer. Figure 7 shows a photograph of an experiment in progress.

\section{Experimental data analysis and discussion}

\subsection{Experimental conditions and data processing}

A total of six tests were conducted during a 40-minute period. The corresponding main channel water velocity measurements by the ADV and the tidal heights are included in Table 1. It shows that the tide height varied from 1.30 to $1.46 \mathrm{~m}$ during the measurements, which is close to high tide conditions. There is a relatively small change compared to the typical tidal range at this location of about $1.6 \mathrm{~m}$. During this time stream wise $(\mathrm{x})$ mean velocities varied from $-0.0628 \mathrm{~m} / \mathrm{s}$ to $-0.1069 \mathrm{~m} / \mathrm{s}$ (i.e. downstream ) while transverse and vertical mean velocities were about an order of magnitude lower than that of the stream wise mean velocity. These velocities occurred at the early stage of ebb tide before the typical maximum stream wise velocity occurring around $0.3 \mathrm{~m} / \mathrm{s}$ to $0.4 \mathrm{~m} / \mathrm{s}$. This part of the tide was chosen because of steady downstream flow with relatively low vertical and transverse velocity components.

After checking all the time series data from the experiment, and noting maximum peak and concentration decay, it was decided to process a 210 -second time series for each test, consisting of 10 seconds before and 200 seconds after the outboard motor left the measuring point. Voltage signals from the concentration probes after 200 seconds would have been too close to the base line voltage to obtain meaningful data.

The observation of all 30 data sets found that the data were affected by instrument data drift. This is a known issue with the Masatoyo probe and is a trade off 
for high frequency response (Madhani and Brown, 2008). Hence it was necessary to remove the drift by fitting with a polynomial function along sections of the data that were influenced by drift, and subtracting the line from the original data set. Finally, the base line was grounded to zero. Figure 8 shows a processed dataset measured by probe 2 in test 5 . It has a relatively high concentration reading and an apparent decay. However, a decay plot with good concentration could not be obtained in 11 datasets, as either the concentration reading was below $4 \mathrm{ppm}$ or the data were badly affected by electronic interference between probes. Hence, only 19 data sets were processed for further analysis.

\subsection{Decay of maximum concentration}

During the analysis, it was found that the plotting of instantaneous concentration data was difficult to interpret, particularly in relation to concentration decay, because there were significant periods of time where the dye plume was not present in the location of the probe. This is the phenomenon of intermittency, which will be discussed in section 3.3. In order to characterize the concentration decay, a graphical representation of maximum concentration versus time was considered more practical as it illustrated the concentration decay more clearly. In this study, the maximum concentration of the data was determined for the entire 210 -second time series where a maximum point was found within a 2 -second interval, as is shown in Figure 8 for probe 2 in test 5 . Since the movement of the dye plume in the wake of the boat was influenced by a propeller-generated swirling flow, the dye was not present at the probe continuously. Hence, some maximum points in the immediate vicinity of the probe may be omitted if the dye happened not to contact the probe. In addition, after a certain time, concentration data fluctuated around the base line and the maximum concentration points during these time periods had to be removed, lest these data points affect the fitting curve. For example, maximum concentration data points after 101 seconds in Figure 8 were omitted when fitted with a trend function.

Because the five probes were located at different distances and different angles from the initial engine position, the first peak concentration signal received by each 
probe was at a different time from the others. Additionally, the swirling movement of the dye concentration made it impossible to predict when the dye would hit the probes. For instance, the measurement of the initial maximum concentration is $1.923 \mathrm{~s}$ in Figure 8. This time delay of initial maximum concentration cannot be deemed as the virtual origin because it is affected by all the reasons explained above. The corresponding reference initial concentration is the highest concentration value, that is, $11.36 \mathrm{ppm}$. Table 2 shows the initial maximum concentration and the corresponding times for the 19 datasets. The general trend is plotted in Figure 9, which shows that the initial concentration decreases with time. Since probe 3 was directly behind the boat and the distance was the smallest, the detection of the initial maximum concentration was relatively quicker than with the other probes. Probes 1 and 5 were located at a greater distance and at a wider angle, so their initial maximum concentration values were smaller and occurred later.

A power function curve was fitted with the maximum concentration points in Figure 8 as

$$
C_{\max }=28.07 t^{-0.651},
$$

with the corresponding dispersion constant of 0.651 . The minimum dilution (maximum concentration) was predicted by IMO (1975) as

$$
D_{\mathrm{IMO}}=\frac{C_{0}}{C}=C_{1}\left(\frac{U L^{2}}{W}\right)\left(\frac{U t}{L}\right)^{0.4} \text {, }
$$

where $C_{1}$ is 0.003 for single discharge and 0.0045 for multiple discharge, $U$ is the boat velocity, $L$ is the boat length, and $W$ is the volume flux of discharged material. When using this IMO equation for the present experimental condition, $C_{1}$ was set as 0.003 and the boat velocity was estimated as $1.35 \mathrm{~m} / \mathrm{s}$. Hence the maximum dye concentration in the wake was

$$
C_{\max }=533.5 t^{-0.4} \text {. }
$$

Note that the amplitude constant before time $t, 533.5$ is about 19 times higher than the value in Eq. (1). The IMO experiment was conducted by discharging pulped 
paper/cardboard slurry from the back of a big barge; this was unlike the present test where the dye solution was injected upstream of the propeller behind a small recreational boat. Furthermore, this release setup may be the reason for the higher dispersion rate in the present experiment than in the IMO prediction.

Concentration decay downstream of a propeller in a laboratory environment has been performed previously (Situ et al. 2010). It was found that the maximum concentration can be fitted with the power law curve as

$$
\frac{C_{\max }}{C_{0}}=6.921 \times 10^{-4}\left(\frac{x}{D_{p}}\right)^{-0.63}
$$

where $D_{\mathrm{p}}$ is the propeller diameter. By assuming that the water velocity is half of the boat velocity, the maximum concentration can be given by

$$
C_{\max }=4.45 t^{-0.63} \text {. }
$$

This suggests that the dispersion constant of field tests agrees well with laboratory tests. It should be noted that the laboratory test was conducted with a stationary propeller and steady water flow. However, in current field test, the boat started at time zero and moved away from the stationary probes. Thus the water velocity at the location of probes experienced a spike and then downgraded to background velocity. This would explain why the constant, i.e., 28.07, in Eq (1) is higher than that in Eq. (5).

Figure $10(\mathrm{a}-\mathrm{f})$ plots the ratio of the maximum concentration points at discrete time periods to the initial maximum concentration values against time, for all 19 tests. The reference time of zero was set as the time after the initial maximum concentration, $t_{\mathrm{I}, \mathrm{max}}$, signal was measured by the probes. Also included in each figure is a power function line fitting all the maximum concentration points in the same test condition. It is noted that the initial maximum concentration values $\left(C_{\max } / C_{\mathrm{I}, \max }=1.0\right.$ at $\left.t=0 \mathrm{~s}\right)$ are not shown in the figures. These data points cannot be used to in fit with power function because they are set as time zero. It was found that the value of the exponent varied from -0.463 to -1.67 , which agrees well with the region of -0.4 to -1.6 found by Ball and Reynolds (1976). The variance of this dispersion constant was due to several 
reasons: 1) the release location; 2) the propeller plume in the wake of the boat; 3) the widespread setup of the five probes; 4) the difference in tide velocity and height, as shown in Table 1; and 5), the effect of the bank. Future research should be done to reduce these effects.

\subsection{Probability density function of the concentration signal}

The probability density function (PDF) of the concentration (scalar) gives a complete description of the state of mixing of two fluids (i.e. uncontaminated creek water and dye emitted from the outboard motor). It also gives information about the proportion of unmixed fluid present (scalar intermittency). Figure $11(\mathrm{a}-\mathrm{f})$ shows PDFs of the conserved scalar for each of the 6 tests in Table 1. Scalar intermittency is measured by the strength of the $\delta$ function at $C=0$ which indicates the proportion of unmixed ambient fluid detected. Bilger et al. (1976) showed that noise can obscure the strength of the $\delta$ function, causing it to spread to a Gaussian curve, and that the standard deviation of the Gaussian is a combined measure of the residual concentration fluctuations in the ambient stream and the electronic noise of the instruments (in this case Komori probes). Thus the spread of the $\delta$ function can result in apparent negative concentrations which are unphysical. Such negative concentrations are seen in Figure 11 (a-f) where the abscissa range commences at $-0.1 \mathrm{ppm}$. It would be possible to subtract the fitted Gaussian curve from the pdf leaving just the $\delta$ function however, it is left here so the reader can visualise how the Gaussian curve was fitted. The residual concentration fluctuations are generally negligible as shown by Bilger et al. (1976). For consistency, the 19 datasets of 210 second time series after removing the drift were used to create the PDFs in Figure $11(\mathrm{a}-\mathrm{f})$ to determine the intermittency. If the time range is shortened, i.e., only the time ranges which include concentration signals are considered, the peaks at $C=0 \mathrm{ppm}$ in Figure 11 will be lower and the probability density, $P_{C}$, on the right side of the peak will become higher. The corresponding intermittency will also decrease.

The standard deviation of the Gaussian profile around $C=0 \mathrm{ppm}$ in Figure 11 for all plumes is shown in Table 2 and represented by lines in Figure 11 (a-f). A 
significant range of intermittency was found. However, upon closer examination, it is clear that most Gaussian curves clustered around standard deviations in the range 0.0203 to $0.0466 \mathrm{ppm}$. The mean of these 17 measurements was $0.0334 \mathrm{ppm}$. The exceptions to this were (test:probe) combinations $(5: 2 ; 5: 3)$ where standard deviations significantly greater than the average were found. Measurements of these two datasets are difficult to interpret and it is not clear if the noise is increased in these cases indicating the presence of intermittency or if the concentration data itself has a Gaussian form in this region. It is also noted the presence of a double peak in (3:1) indicating that the $\delta$ function at $C=0$ has not blended in with the pdf of the dye and can be seen quite separately. The Gaussian fitting procedure was used on the left hand peak only. After carefully fitting to the noise around $\mathrm{C}=0 \mathrm{ppm}$, it was found that the intermittency of (3:1) was 0.239 , which is significantly less than the minimum of the other data sets value of 0.50 . Intermittency is an important parameter of plume behaviour (Sawford, 1987; Brown and Sawford, 2000). The authors are not aware of any field measurements of intermittency in water reported in the literature.

In Table 2, most of the data have intermittency range of 0.50 to 0.95 except the only (test:probe) combination (3:1) discussed above. Thus it is inferred that the majority of the tests had dye present for less than $50 \%$ of the time. This indicates that the dye plume meandered away from the probe or that it was complex in structure with regions of mixed and unmixed dye. Observations of the plume during the experiment confirm both these possibilities. The field-based PDFs and the intermittency presented above are valuable for the development of dispersion models for emissions from boats and outboard motors. No such field-based data have been found in the literature.

\section{Conclusion}

To understand the mixing and dispersion of pollutants emitted from an outboard motor, field tests were conducted in a small subtropical waterway, Eprapah Creek, at Victoria Point, Queensland, Australia. Organic dye was injected upstream of a boat propeller and the dye concentration was measured by Komori concentration probes in the wake of the propeller plume. The results of the experiment found that, because of the 
intermittency phenomenon, maximum concentration in a certain time period instead of instantaneous concentration should be used to describe dispersion. The decay curves of the points of maximum concentration were fitted with power law functions. The corresponding dispersion constants were in the region of 0.463 to 1.67 , which agrees well with the literature. The variation in dispersion was due to the combined effect of the dye release location, the boat propeller, the probe setup, the tide change and the creek bank. High intermittency was further confirmed by examining the probability density function of the concentration signal. This showed that dye concentration was detected for less than 50 percent of the time, indicating in-homogeneity.

\section{Acknowledgements}

The authors would like to thank the contributions from QUT students Tek Jin Chin, Nicholas Lee who conducted the field trip and the assistance from QUT technicians David McIntosh, Glen Turner, Dave Burgess, Jon James, Jim Grady, Viv Ashton, Trevor Laimer, and Stephen Steggall. 


\section{References}

Ball, J., Reynolds, T.D., 1976. Dispersion of liquid waste from a moving barge. J. Water Pollut. Control. Fed. 48, 2541-2548.

Bilger, R.W., Antonia, R.A., Screenivasan, K.R., 1976. Determination of intermittency from the probability density functions of a passive scalar. Phys. Fluids 19, 1471-1474.

Brown, R.J., Sawford, B.L., 2000. Probability density function integrals and smallscale mixing in turbulent plumes. Boundary-Layer Met. 97, 219-249.

Chanson, H., Brown, R., Ferris, J., Ramsay, I., Warburton, K., 2005. Preliminary measurements of turbulence and environmental parameters in a sub-tropical estuary of eastern Australia. Environ. Fluid Mechanics. 5, 553-575.

Chou, H.T., 1996. On the dilution of liquid waste in ships' wakes. J. Mar. Sci. Technol. 149-154.

Hyman, M., Rohr, J., Schoonmaker, J., Ratcliffe, T., Chadwick, B., Richter, K., Jenkins, S., Wasy, J., 1995. Mixing in the wake of an aircraft carrier. Proceedings of OCEANS '95 MTS/IEEE. Challenges of our changing global environment 3, 1730-1744.

International Maritime Organization, 1975. Procedures and arrangements for the discharge of noxious liquid substances. Method for calculation of dilution capacity in the ship's wake. IMCO document MEPC III-7, International Maritime Organization, London.

Jones, A.B., Prange, J., Dennison, W.C., 1999. An assessment of the ecological health of Eprapah Creek. Final data report, online: http://ian.umces.edu/adrian/jones_etal_eprapahck_report_1999.pdf.

Katz, C.N., Chadwick, D.B., Rohr, J., Hyman, M., Ondercin, D., 2003. Field measurements and modeling of dilution in the wake of a US navy frigate. Mar. Pollut. Bull. 46, 991.

Kelly, C.N., Ayoko, G.A., Brown, R.J., Swaroop, C.R., 2005. Underwater emissions from a two-stroke outboard engine: a comparison between an EAL and an equivalent mineral lubricant. Mat. Des. 26, 609-617. 
Kimo International Environmental Organization Sweden, 2004. Pollution from twostroke outboard engines.

http://www.kimointernational.org/Portals/0/Files/RESL102D.pdf

Lewis, R.E., 1985. The dilution of waste in the wake of a ship. Water Res. 19, 941 -945 .

Madhani, J.T., Brown, R.J., 2008. A scalar concentration (Komori) probe for measuring fluctuating dye concentration in water. WSEAS Trans. Fluid Mechanics. 3, 224-233.

Masters, G.M., 1998. Introduction to environmental engineering and science, second ed. Prentice Hall, New Jersey.

QEPA The State of Queensland Environmental Protection Agency, 2004. Water quality monitoring in Redland waterways. Online: http://www.derm.qld.gov.au/environmental_management/water/water_quality_ monitoring/projects/water_quality_monitoring_programs/water_quality_in_red lands_waterways/\#Eprapah_Creek

Sawford, B. L., 1987. Conditional concentration statics for surface plumes in the atmospheric boundary layer. Boundary-Layer Met. 38, 209-223.

Situ, R., Brown, R. J., Loberto, A., 2010. Experimental study of the concentration field of discharge from a boat propeller. Environ. Fluid Mech. 10, 657-675.

Trevethan, M., Chanson, H., Brown, R. J., 2008a. Turbulence characteristics of a small subtropical estuary during and after some moderate rainfall. Estuarine Coastal Shelf Sci., 79, 661-670.

Trevethan, M., Chanson, H., Brown, R. J, 2008b. Turbulent measurements in a small subtropical estuary with semidiurnal tides. J. Hydraulic Eng. 134, 1665-1670.

Warrington, P., 1999. Impacts of outboard motors on the aquatic environment. www.nalms.or/bclss/impactsoutboard.htm. 


\section{Captions of Tables and Figures}

Table 1. Experimental conditions.

Table 2. Test results of 19 datasets.

Figure 1. Aerial photograph of Eprapah Creek estuary (courtesy of Queensland Department of Natural Resources and Mines, 2001).

Figure 2. Schematic diagram of equipment setup.

Figure 3. Concentration probe holder.

Figure 4. Schematic diagram of field deployment.

Figure 5. Transect of Eprapah $\mathrm{Ck}$ profile at deployment locationof instruments setup at low tide.

Figure 6. Schematic diagram of dye injection design.

Figure 7. Photography of experiment in process.

Figure 8. Example of concentration decay with power law fit.

Figure 9. Initial maximum concentration.

Figure 10. Time decay of maximum concentration ratio.

Figure 11. Probability density function of instantaneous concentration. 
Table 1

\begin{tabular}{|c|c|c|c|c|c|}
\hline \multirow{2}{*}{ Test Number } & \multirow{2}{*}{ Starting time } & \multicolumn{2}{|c|}{ Main Channel Mean Velocities (m/s) } & \multirow{2}{*}{ Tide Height } \\
\cline { 3 - 5 } & & $V_{\mathrm{x}}$ & $V_{\mathrm{y}}$ & $V_{\mathrm{z}}$ & $(\mathrm{m})$ \\
\hline 1 & $14: 40$ & -0.0628 & -0.00579 & 0.0037 & 1.46 \\
\hline 2 & $14: 46$ & -0.1069 & -0.0285 & -0.0151 & 1.40 \\
\hline 3 & $14: 48$ & -0.1016 & -0.0247 & -0.0291 & 1.40 \\
\hline 4 & $14: 56$ & -0.0062 & -0.0188 & -0.0090 & 1.34 \\
\hline 5 & $15: 03$ & -0.0668 & -0.0092 & -0.0055 & 1.30 \\
\hline 6 & $15: 17$ & -0.0807 & -0.0150 & -0.0070 & 1.30 \\
\hline
\end{tabular}


Table 2

\begin{tabular}{|r|r|r|c|c|c|}
\hline \multicolumn{1}{|c|}{ Test } & Probe & $\begin{array}{c}C_{0, \max } \\
(\mathrm{ppm})\end{array}$ & $\begin{array}{c}t_{0, \max } \\
(\mathrm{sec})\end{array}$ & $\begin{array}{c}\text { Standard } \\
\text { deviation }\end{array}$ & Intermittency \\
\hline 1 & 2 & 11.38 & 24.026 & 0.0312 & 0.9319 \\
\hline & 3 & 12.84 & 20.915 & 0.0361 & 0.8545 \\
\hline & 4 & 13.45 & 11.447 & 0.0358 & 0.9484 \\
\hline 2 & 2 & 12.13 & 13.7 & 0.0466 & 0.8189 \\
\hline & 3 & 13.03 & 1.2 & 0.0260 & 0.8821 \\
\hline & 4 & 10.41 & 19.1 & 0.0203 & 0.8552 \\
\hline & 5 & 6.48 & 24.2 & 0.0257 & 0.8515 \\
\hline 3 & 1 & 3.43 & 69.0 & 0.0229 & 0.2388 \\
\hline & 2 & 11.73 & 7.8 & 0.0461 & 0.7353 \\
\hline & 3 & 12.96 & 4.1 & 0.0344 & 0.7733 \\
\hline & 4 & 3.93 & 59.2 & 0.0286 & 0.8815 \\
\hline 4 & 1 & 1.31 & 10.7 & 0.0262 & 0.6883 \\
\hline & 2 & 9.86 & 3.8 & 0.0333 & 0.7332 \\
\hline & 3 & 8.30 & 0.7 & 0.0364 & 0.7163 \\
\hline 5 & 1 & 4.93 & 26.8 & 0.0346 & 0.4972 \\
\hline & 2 & 11.36 & 1.9 & 0.0961 & 0.5867 \\
\hline & 3 & 11.94 & 0.2 & 0.0576 & 0.6948 \\
\hline & 4 & 5.37 & 4.0 & 0.0372 & 0.7033 \\
\hline 6 & 3 & 12.48 & 2.9 & 0.0461 & 0.8232 \\
\hline
\end{tabular}


Figure 1

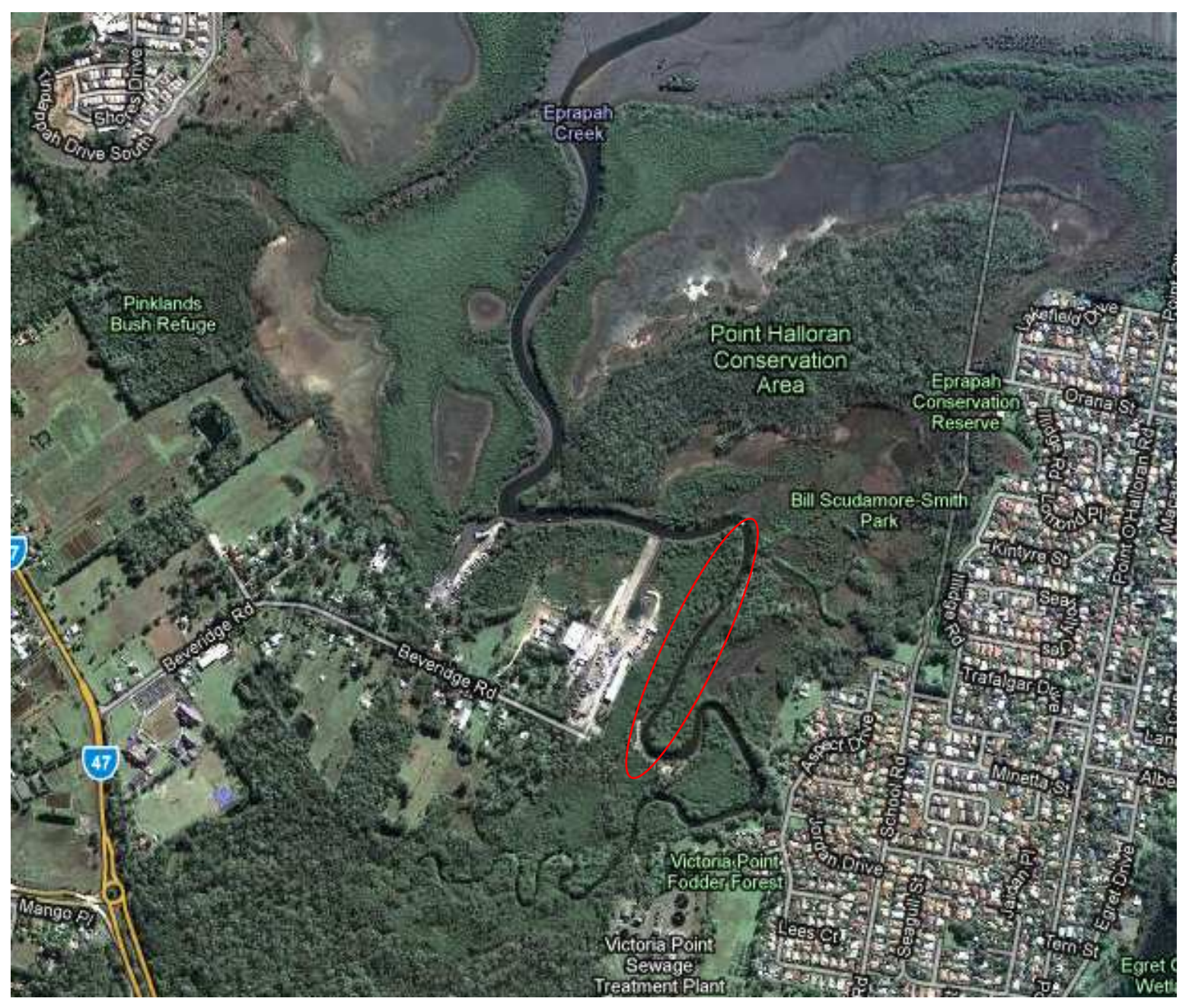


Figure 2

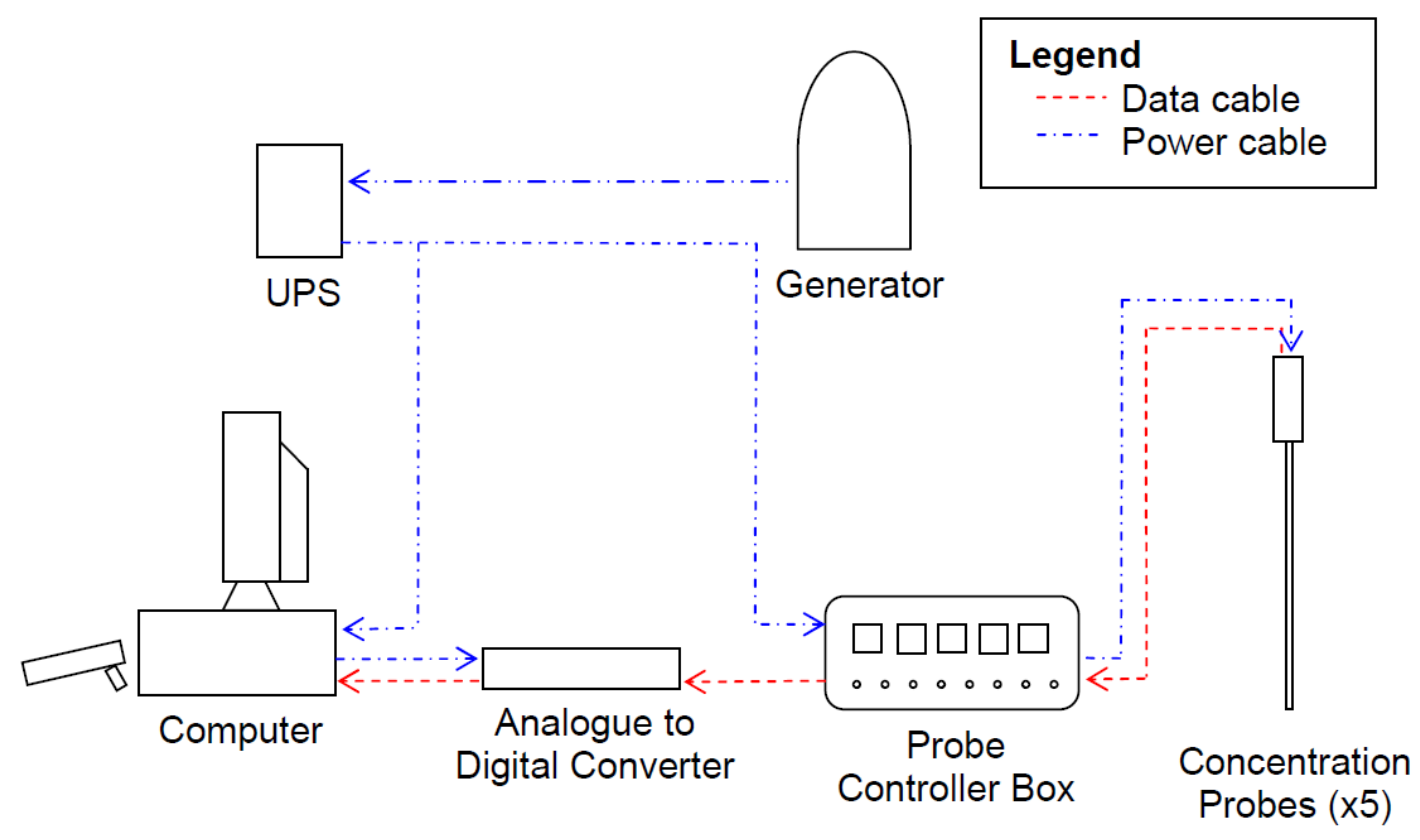


Figure 3

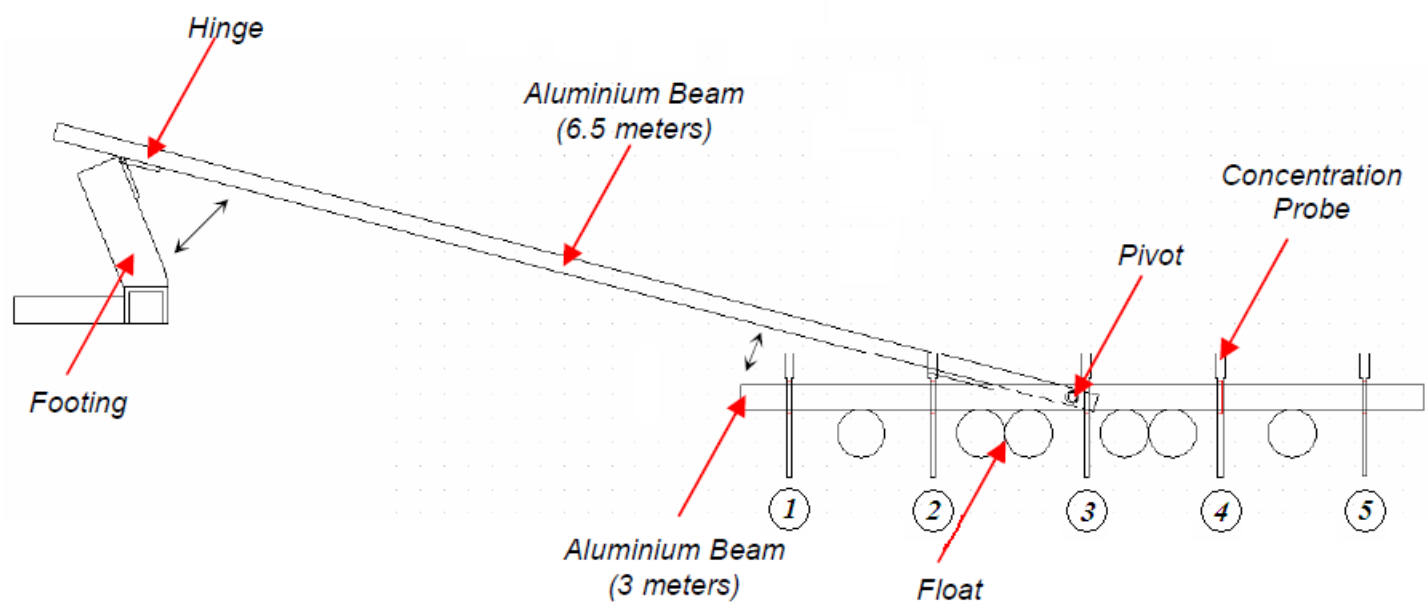


Figure 4

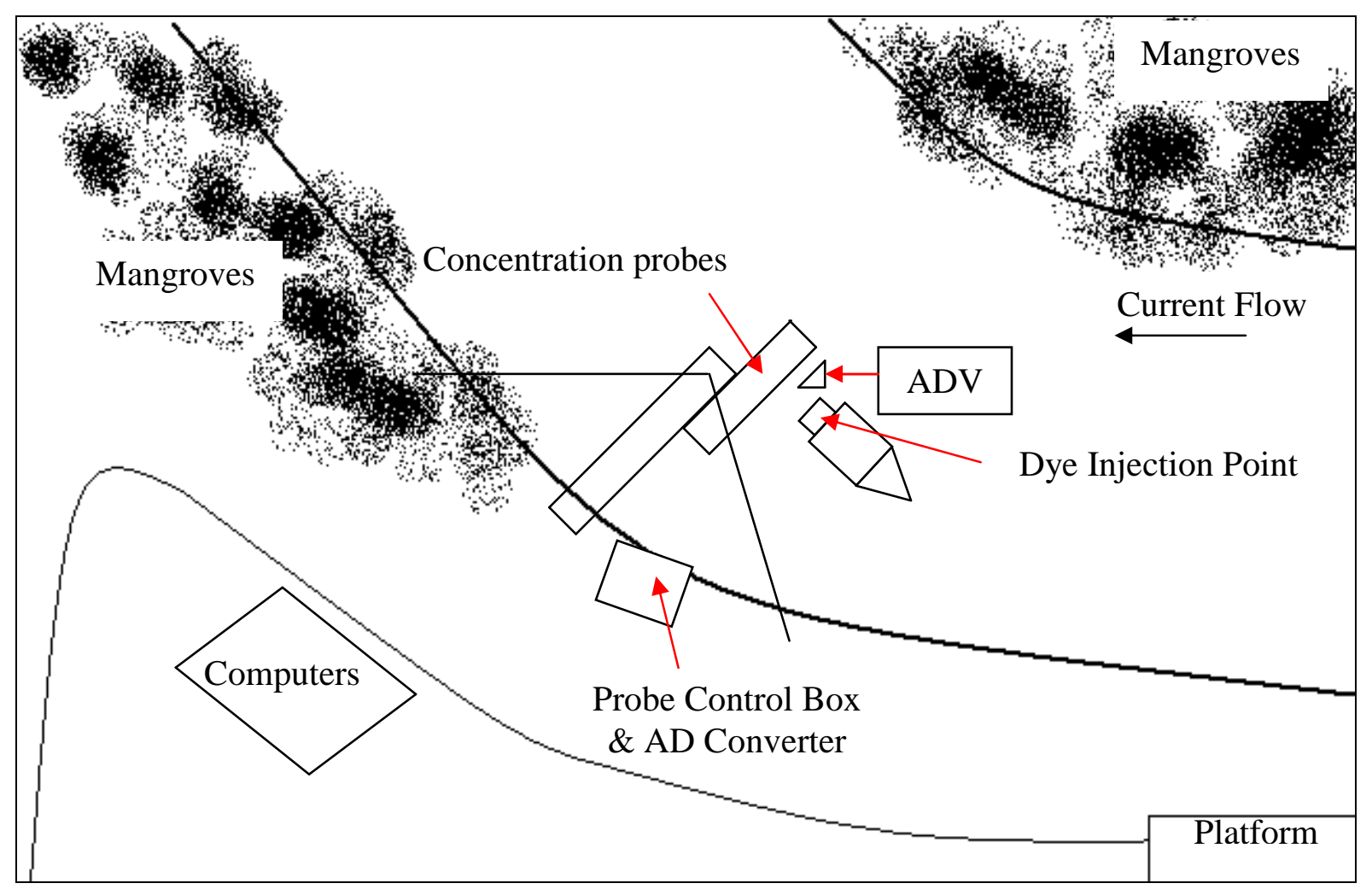


Figure 5

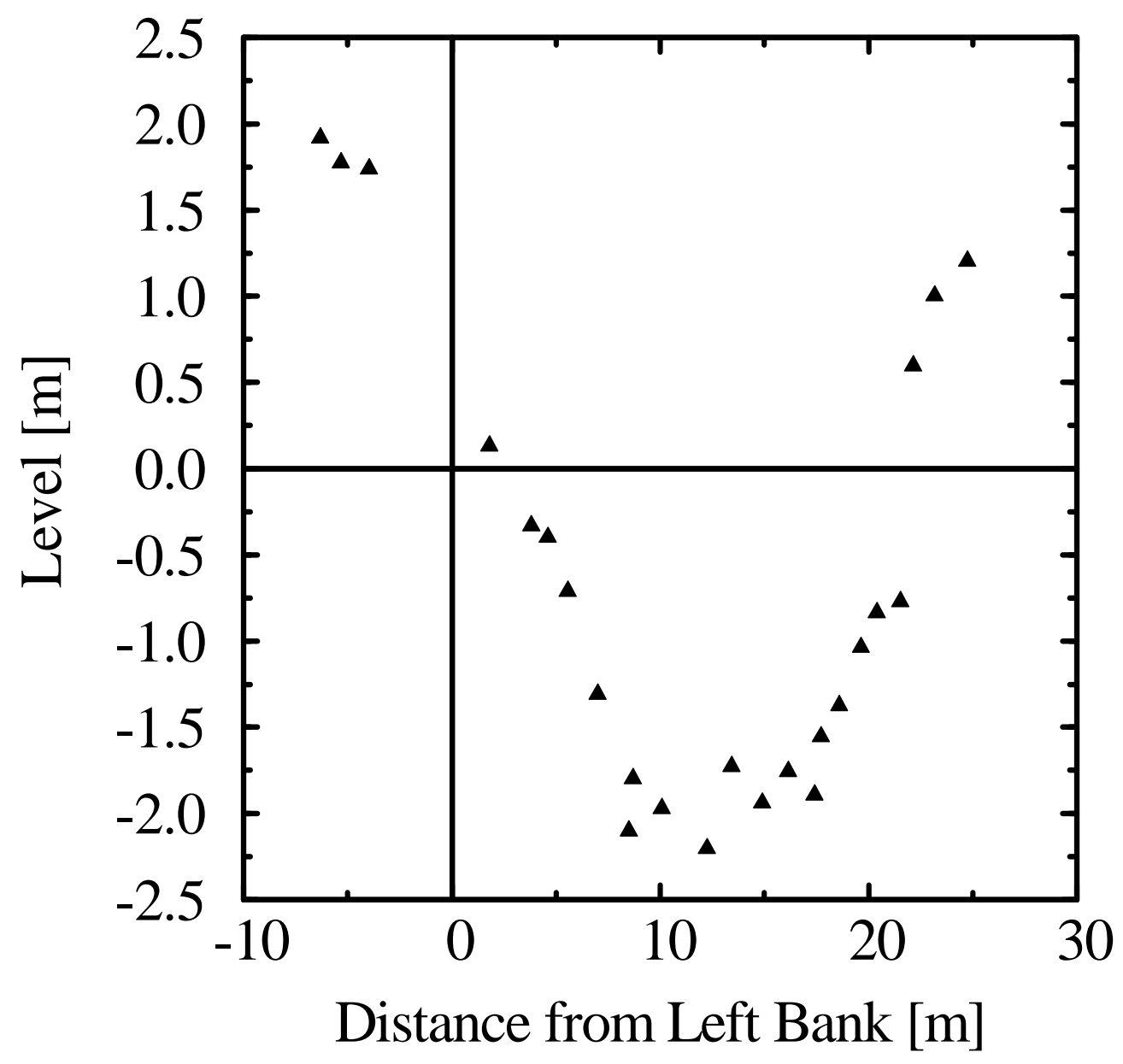


Figure 6

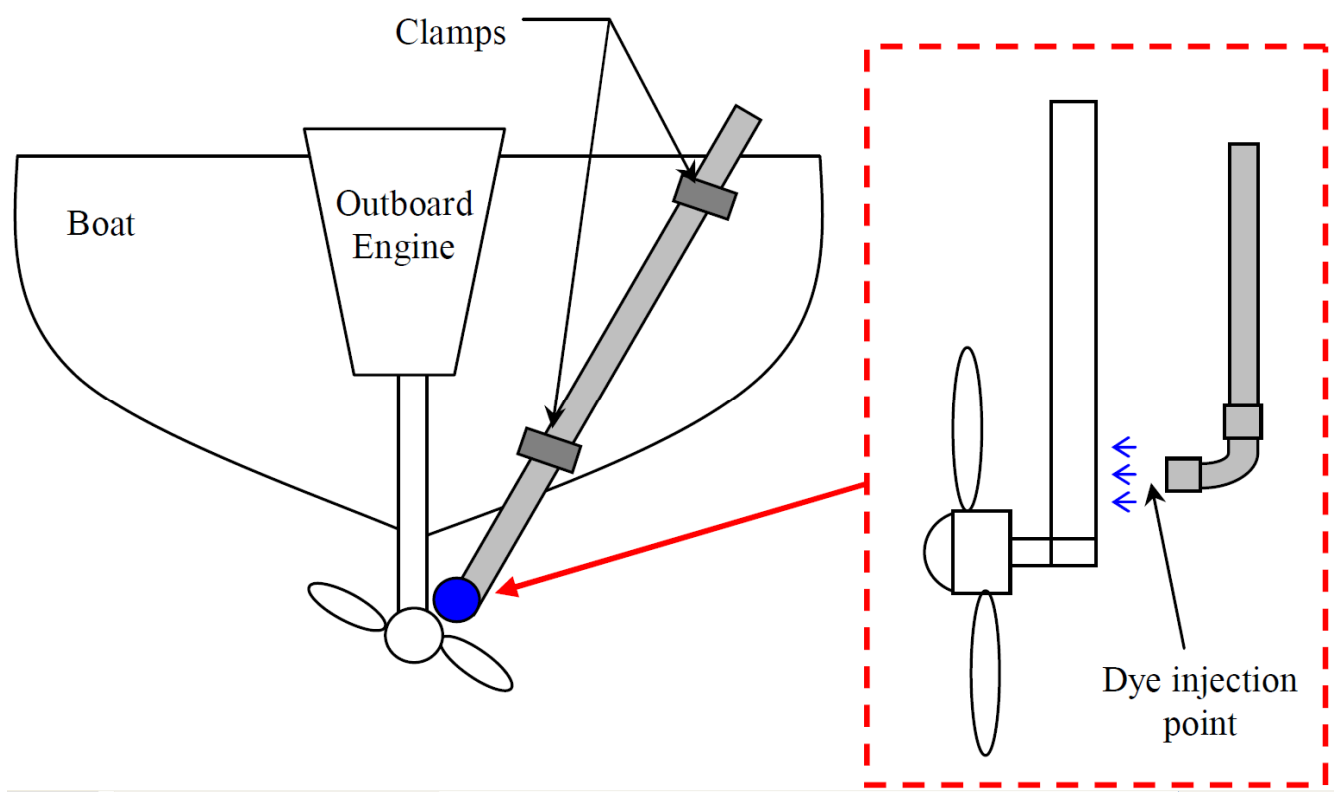


Figure 7

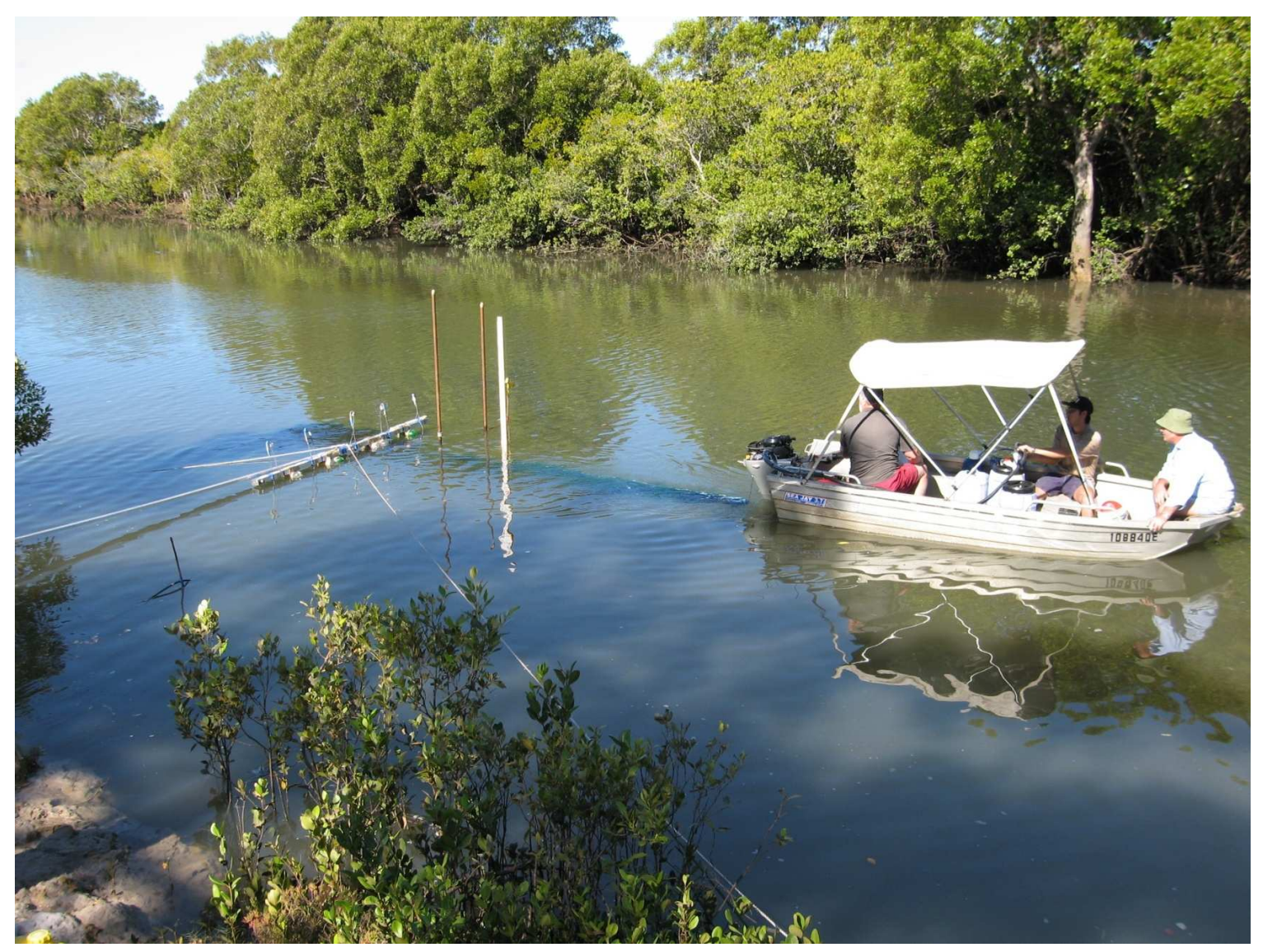


Figure 8

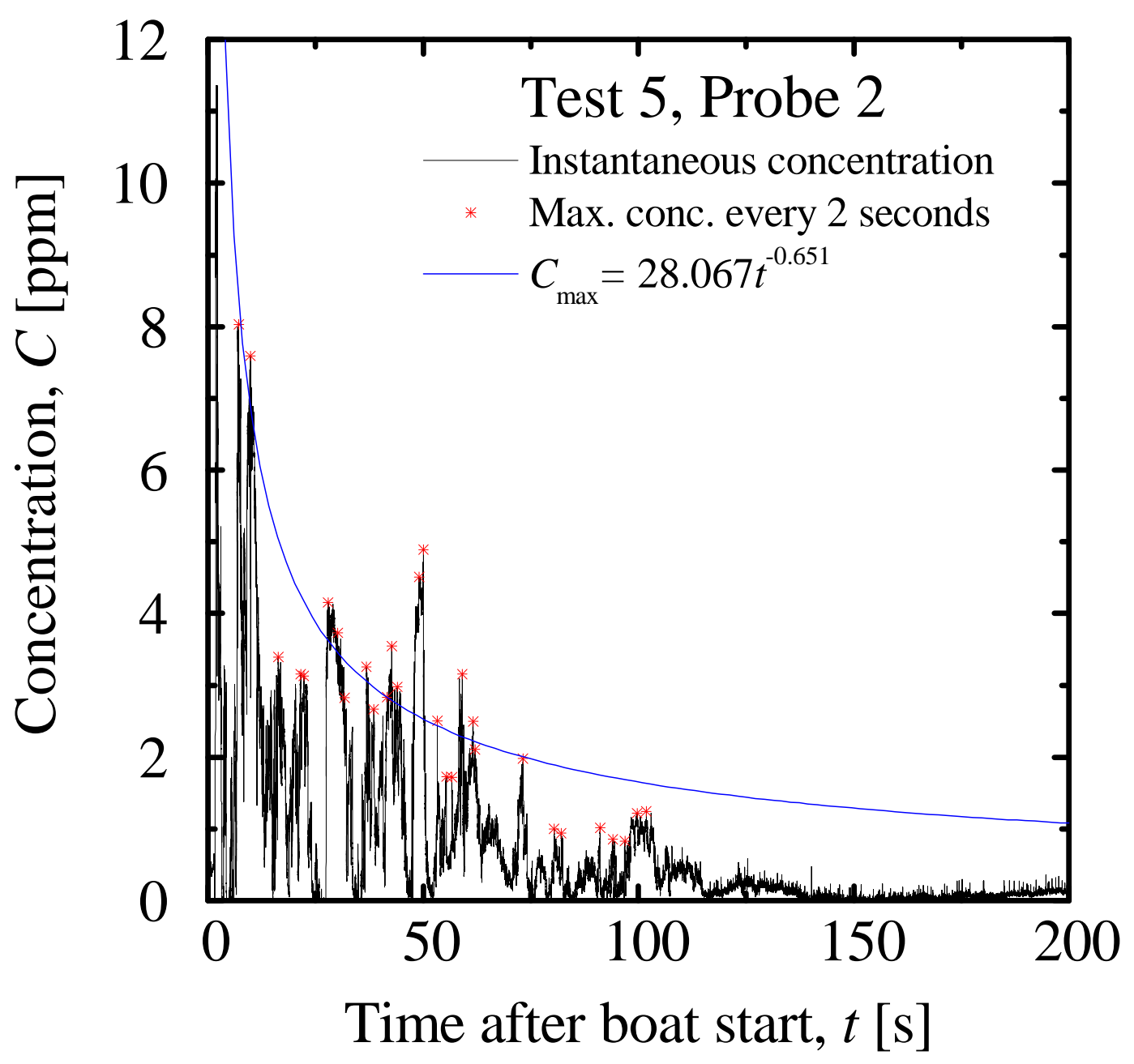


Figure 9

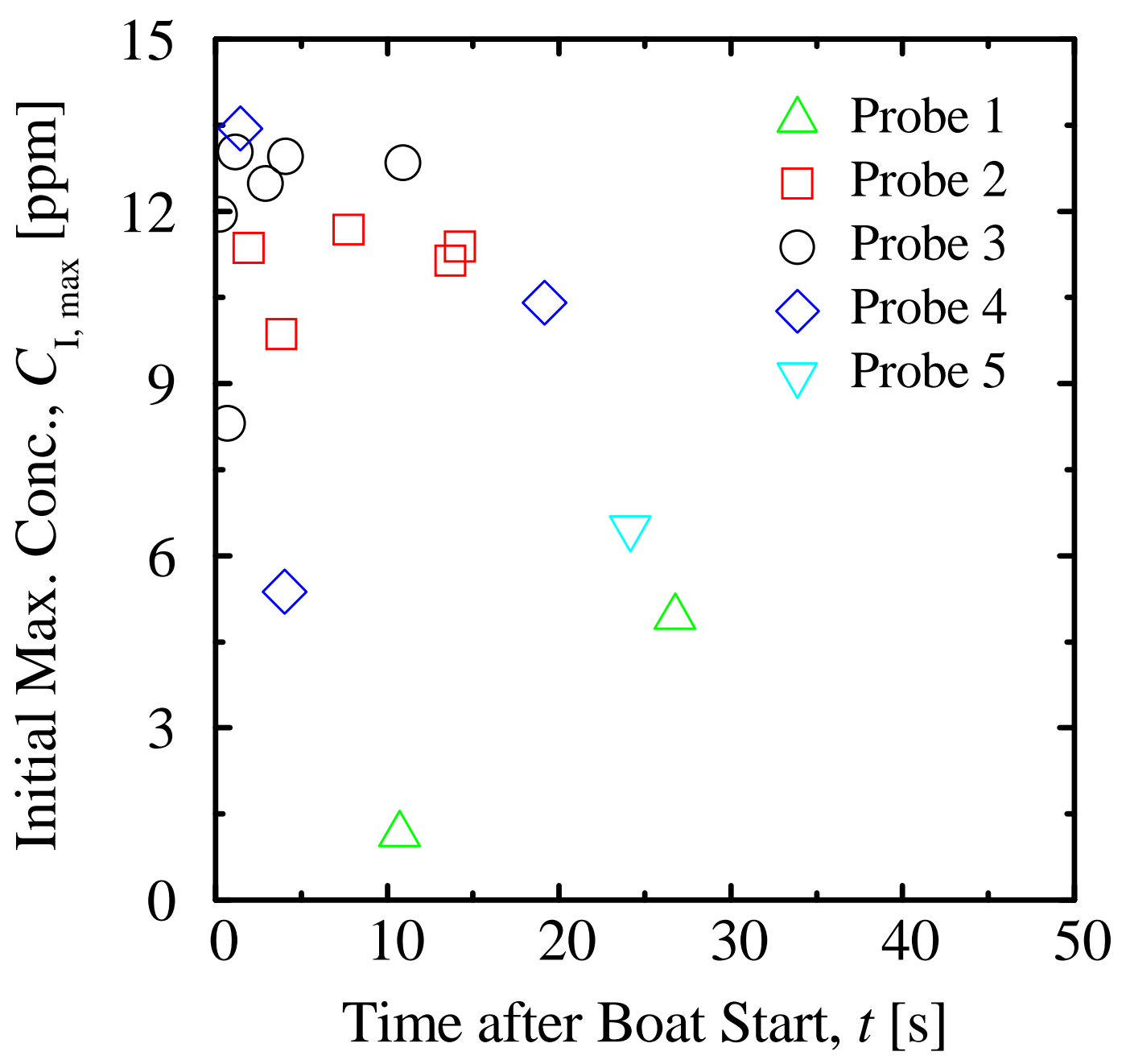


Figure 10
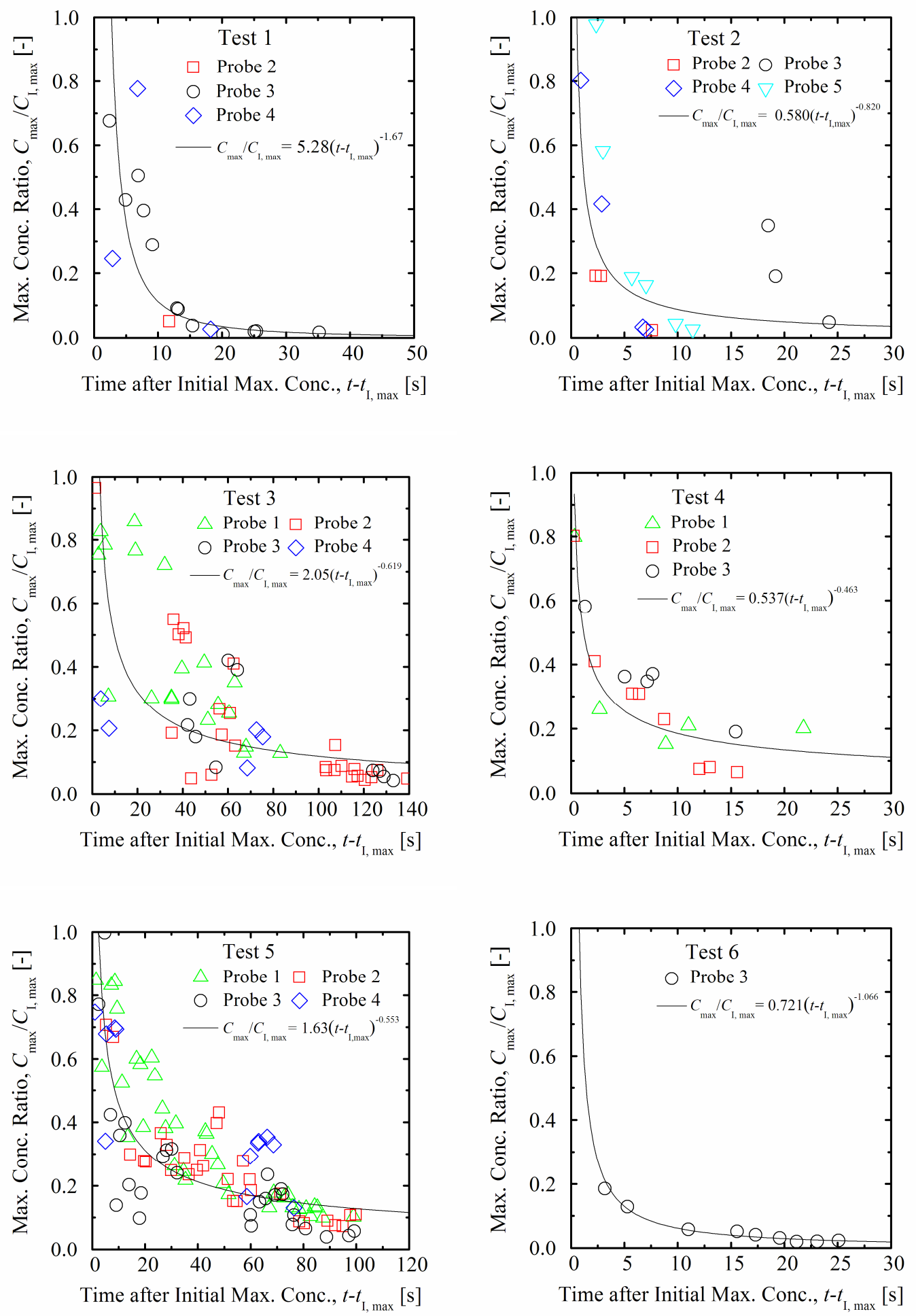
Figure 11

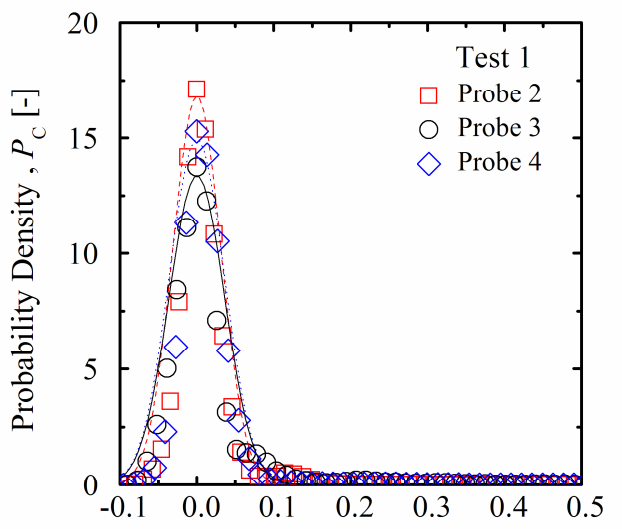

Instantaneous Concentration Readings, $C$ [ppm]

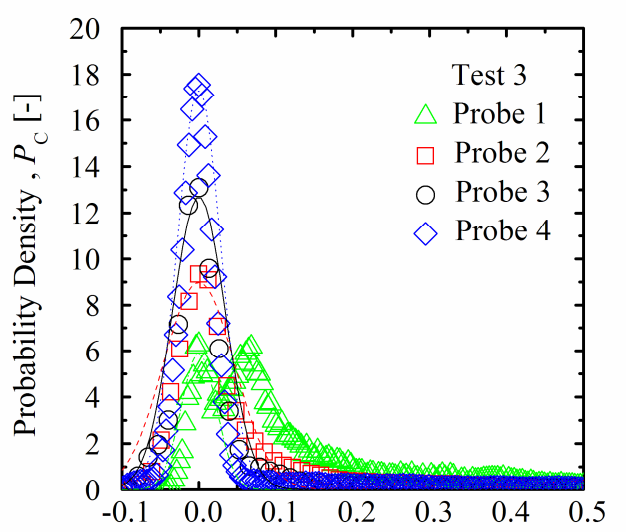

Instantaneous Concentration Readings, $C$ [ppm]

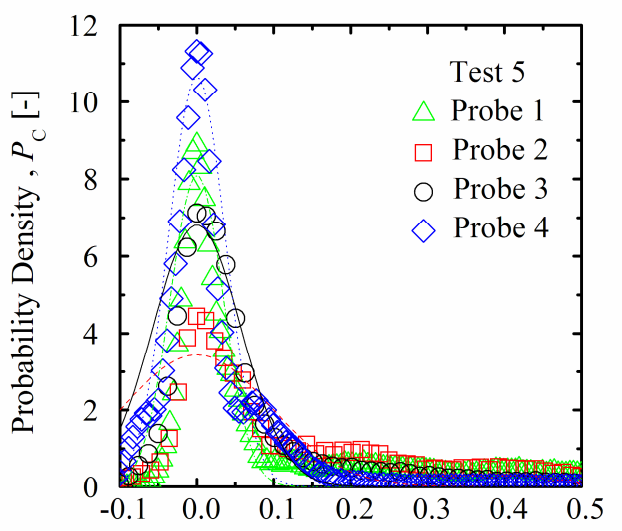

Instantaneous Concentration Readings, $C$ [ppm]
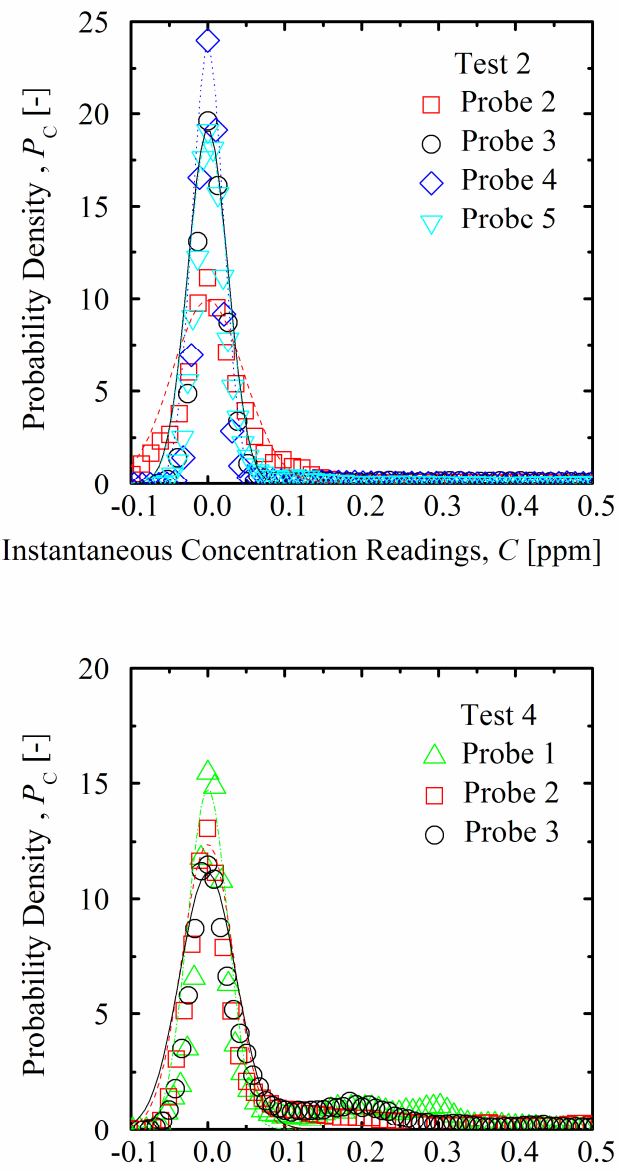

Instantaneous Concentration Readings, $C$ [ppm]

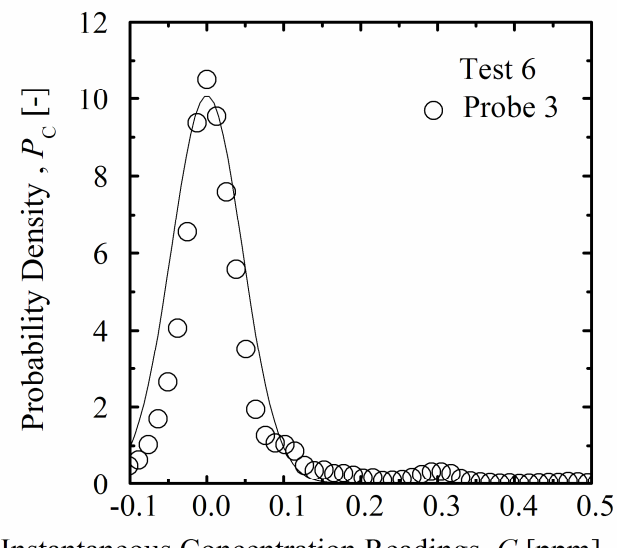

